\title{
A INTERVENÇÃO DA TERAPIA COGNITIVO- COMPORTAMENTAL NO ADOECIMENTO DECORRENTE DA INSÔNIA
}

Natália Araújo Silva

Hugo Christiano Soares Melo ${ }^{3}$

\section{RESUMO}

O presente estudo procurou descrever as principais características do sono e da insônia, além de apresentar técnicas da Terapia Cognitivo-Comportamental (TCC) para o tratamento da insônia. A metodologia utilizada foi qualitativa de referencial bibliográfico. $O$ objetivo deste trabalho foi discutir a atuação do profissional de psicologia a partir de técnicas da TCC o que se pode fazer para amenizar o sofrimento do paciente portador da insônia. Percebe-se que as alterações do sono são bastante comuns na atualidade, sendo a insônia a queixa que aparece com maior frequência causando grande prejuízo na vida do indivíduo. O tratamento não farmacológico da insônia baseado nas técnicas de TCC vem ganhando cada vez mais espaço, por proporcionar a reversão da causa mantenedora da insônia. O estudo evidenciou que atualmente se trabalha muito nesta questão mais ainda existem lacunas a serem preenchidas desde o diagnóstico, evolução até o tratamento da insônia.

Palavras-chave: Sono. Insônia. Terapia Cognitivo-Comportamental. Tratamento.

\section{ABSTRACT}

The present study tried to describe the main characteristics of sleep and insomnia, and the present techniques of cognitive-behavioral therapy (CBT) for the treatment of insomnia._The methodology was qualitative bibliographic references. The objective of this to discuss the role of the professional review was to discuss the role of the psychologist from the CBT in order to alleviate the suffering of the patient with insomnia. It is clear that sleep disorders are quite common nowadays, and insomnia complaint that appears most often causing great damage in people's lives. The non-pharmacological treatment of insomnia based on CBT techniques is

\footnotetext{
${ }^{3}$ Endereço eletrônico de contato: hugo.some@gmail.com
}

Volume 1, Número 1 - Abril, 2015. 
gaining more space because it provides a measure that maintains the reversal of the cause of insomnia. This study showed that actually we care a lot more about this issue but there still are gaps to be filled since the diagnosis and progression to the treatment of insomnia.

Kewords: Sleep. Insomnia. Cognitive-behavioral therapy. Treatment.

\section{INTRODUÇÃO}

A insônia é um distúrbio do sono que afeta grande parte da população geral, influenciando de maneira significativa diretamente na qualidade de vida do indivíduo. No decorrer do curso, surgiu um interesse em pesquisar sobre as possíveis intervenções que o psicólogo pode oferecer no tratamento da insônia percebido através da necessidade que se existe atualmente, sendo que a pesquisa se mostra importante não só apenas para fins acadêmicos, mas também para fornecer subsídios para uma futura atuação profissional, e promover uma possível reflexão entre os leitores.

A metodologia utilizada no trabalho foi a revisão da literatura do tema abordado, incluindo livros, artigos, monografias, dissertações e teses, foram utilizados também dados disponíveis em bibliotecas e em sítios da internet, como o scielo, dentre outros; por meio de palavras-chave como: psicologia e insônia, terapia cognitivo-comportamental e insônia, fisiologia do sono, fisiologia da insônia, foram utilizados artigos a partir do ano de 2000 até 2012. O período de coleta de materiais se estendeu de setembro de 2011 a junho de 2012, posteriormente foi feita uma análise dos materiais coletados para se verificar a relevância dos mesmos na elaboração do artigo.

Este estudo teve como objetivo geral discutir sobre a atuação do psicólogo no tratamento dos distúrbios do sono mais especificamente, no tratamento da insônia, caracterizar o sono normal e a insônia, citar as ações do profissional de psicologia clínica neste contexto, e enumerar benefícios e técnicas da atuação do psicólogo no tratamento da insônia.

Para melhor execução dos objetivos propostos utilizou-se da metodologia qualitativa de referencial bibliográfico, focando assim responder: $O$ que é o sono normal? $O$ que caracteriza a insônia? Quais contribuições o psicólogo pode oferecer no tratamento da Insônia?

Para um melhor entendimento o artigo encontra-se estruturado em três seções, inicialmente serão esclarecidas algumas questões sobre o sono, dando seguimento será

Volume 1, Número 1 - Abril, 2015. 
abordada a insônia, logo após será descrito o que se cabe ao tratamento da insônia dentro da abordagem cognitivo-comportamental, e por fim a conclusão.

\section{O SONO E A SUA COMPREENSÃO}

\subsection{Sono Normal}

O sono caracteriza-se por ser um estado regular, recorrente e com uma grande facilidade reversível onde há um aumento do limiar em resposta a estímulos externos ${ }^{(1)}$. É um estado vital, que combina processos ativos e altamente organizados composto por dois estados fisiológicos o sono sem movimentos rápidos dos olhos (NREM) e o sono com movimentos rápidos dos olhos (REM). ${ }^{(2)}$

Os períodos cíclicos do sono são regulares, ao longo da vida os padrões vão mudando, ao nascer o sono REM representa $50 \%$ no tempo total do sono, a partir dos quatro meses de idade esse tempo do sono REM cai para abaixo dos $40 \%$, a distribuição do sono permanece constante de um modo relativo no decorrer do tempo, no entanto nas pessoas com idade mais avançada há uma redução nos períodos do sono. ${ }^{(1)}$

Garantindo equilíbrio entre os períodos de sono e de vigília estão envolvidos três processos básicos: os processos circadianos, sua regulação é feita pelo núcleo supraquiasmático (NSQ) do hipotálamo anterior, controlando a variação de alta e baixa propensão de sono durante as 24 horas do dia, já os processos homeostáticos influenciam a intensidade de sono podendo ser influenciados pelo período da vigília anterior, e por fim os processos ultradianos que definem os períodos de alternância de sono NREM e do sono REM, dentro do processo do sono. ${ }^{(2)}$

\subsection{Funções do Sono}

De acordo com Sadock e Sadock(1) o sono exerce uma função de restauração homeostática, mantendo o equilíbrio do corpo humano, sendo crucial na termorregulação e também para conservar energia, além do mais o sono NREM após exercícios e também períodos de extrema debilidade, aumenta, satisfazendo assim as necessidades metabólicas. Martino $^{(3)}$ considera que o sono exerce um papel fundamental na reposição de energia e também no desempenho físico mental.

Durante o período do sono são reparadas várias funções do organismo, pelo fato de o sono contribuir significativamente para que os componentes psicológicos estejam em perfeita harmonia com o funcionamento fisiológico. ${ }^{(4)}$

\subsection{A fisiologia do Sono}

Volume 1, Número 1 - Abril, 2015. 
Segundo Aloé et al. ${ }^{(5)}$ o sono é um complexo estado comportamental constituído pela variação dos estágios REM e NREM. De acordo com Sadock e Sadock ${ }^{(1)}$, no estágio (NREM) as funções fisiológicas são mais reduzidas do que normalmente ocorre na vigília, ele se caracteriza por movimentos involuntários do corpo durante o sono e também por um maior estado de quietude quando a ser comparado a vigília. Para Vigeta(6) é o sono quieto, ou também sono de ondas lentas responsável pela restauração física. É composto por quatro estágios:

Estágio 1: É o estágio conhecido como sendo um estágio de transição, ou também meio sono, por fazer a transição entre o estado da vigília e o sono.(2)

Estágio 2: É caracterizado pela presença de fusos no sono e também pela ausência de movimentos dos olhos. ${ }^{(7)}$

Estágios 3 e 4: De acordo com Martino(3) são considerados os estágios de sono lento e mais profundos. Para Fernandes ${ }^{(8)}$, ocorrem na primeira metade da noite alternando aos outros estágios, pela manhã ou na segunda metade da noite tendem a não aparecer dando espaço aos estágios I e II.

No sono NREM, os estágios 3 e 4 são bem semelhantes, pois são distintos apenas pela proporção das ondas, e ambos são chamados de sono de ondas lentas. ${ }^{(2)}$

O sono REM se caracteriza por um nível elevado de atividade cerebral e também por fases de atividades fisiológicas compatíveis com os da vigília. Após 90 minutos depois de se iniciar o sono, o NREM abre espaço para a primeira aparição do sono REM, é um período de latência com cerca de 90 minutos que acontece nos adultos que não possuam tipo de algum de distúrbio no sono. ${ }^{(1)}$

\subsection{Privação e Necessidade de Sono}

Longos períodos de privação de sono podem desencadear em uma grande desordem no corpo humano, provocando alucinações ou até mesmo delírios. ${ }^{(1)}$ Quando um indivíduo é privado de sono mesmo que tente dormir por mais tempo para recuperar o tempo perdido isto se torna em vão e pode ainda por prejudicar as funções naturais do organismo. ${ }^{(4)}$

Vigeta $^{(6)}$ destaca que a privação de sono acaba por afetar várias funções do sistema nervoso central; longos períodos de vigília prolongada poderão acarretar o funcionamento progressivo de forma não adequada dos processos mentais, podendo causar até atividades comportamentais fora da normalidade.

Em contra partida a essas privações existem pessoas que não precisam de muitas horas de sono para funcionar de forma adequada, devido ao fato de que a necessidade individual de sono é variável. ${ }^{(1)}$

De acordo com Rios et al. ${ }^{(4)}$, fatores genéticos, psicológicos ambientais e culturais também exercem forte influência na quantidade de sono, que tende a cair entre as pessoas Volume 1, Número 1 - Abril, 2015. 
mais velhas, até mesmo pelo fato que estes já não possuem mais uma grande população neuronal de ordem natural.

\subsection{Alterações do Sono}

Os distúrbios no sono são bastante comuns, e representam um significativo problema de saúde pública, cerca de um terço da população tem dificuldade para dormir e isso tende a ficar cada vez mais grave com o avanço da idade. ${ }^{(9)}$

Para Vigeta ${ }^{(6)}$, a perda de sono tanto parcial quanto crônica pode acarretar em um grande mal para o indivíduo, pelo fato de que na maioria das vezes tais queixas são consideradas como normais, não sendo dada devida importância por parte da medicina, por dificuldade no diagnóstico, vez que o sono não se localiza em nenhum órgão passível de exame.

Atualmente mesmo com a grande demanda de pacientes insones ainda existem pessoas que não procuram atendimento, muitas das vezes se automedicando ou ignorando que haja um tratamento adequado retardando ainda mais sua condição.

Rios et al. ${ }^{(4)}$, enfatizam que diagnosticar precocemente qualquer alteração do sono é de grande valia visto que o diagnóstico poderá prevenir problemas secundários; é de fundamental importância a avaliação clínica, o exame polissonográfico também constitui uma ferramenta significativa para esclarecer questões que estejam obscuras em relação ao distúrbio do sono.

Os métodos que podem auxiliar no diagnóstico da investigação das alterações do sono, estão dispostos desde a avaliação do paciente até aos registros polissonográficos, métodos estes que serão cruciais para o manejo da futura intervenção. ${ }^{(6)}$

Várias dificuldades são encontradas ao tratamento das patologias do sono, a demora pela procura de um tratamento adequado pode acabar agravando o quadro da patologia, o transtorno que aparece com maior frequência é a insônia, várias podem ser as causas desencadeantes da mesma, sendo que o tratamento irá depender de uma busca minuciosa da etiologia do problema. O papel do psicólogo no tratamento dessas alterações do sono é crucial, pois este profissional é um agente fundamental na condução do paciente desde a avaliação até o tratamento. ${ }^{(4)}$

\section{A INSÔNIA}

\subsection{Definição e Classificação da Insônia}

Volume 1, Número 1 - Abril, 2015. 
Incorporados às alterações do sono, são encontrados os transtornos primários do sono, onde a etiologia dos mesmos não está relacionada a um exame psiquiátrico, a uma doença médica, ou também a dependência de fármacos, ou seja, está intrinsecamente ligada a alterações de mecanismos que regulam o sono e a vigília, que podem ser agravados por fatores de condicionamento. ${ }^{(10)}$

De acordo com o DSM - IV (APA, 2003), a principal característica da Insônia Primária é a queixa de dificuldade para iniciar ou manter o sono e também a sensação de um sono não reparador, com duração mínima de um mês que irá causar prejuízo social e ocupacional, além de afetar outras demais áreas importantes na vida do indivíduo. Cavadas e Ribeiro, (2010) definem a insônia como sendo uma experiência subjetiva de sono de forma inadequada e qualidade limitada.

\begin{abstract}
A insônia primária se associa habitualmente a um aumento do nível de alerta fisiológico e psicológico durante a noite, junto a um condicionamento negativo para dormir. A preocupação intensa e o mal estar relacionados com a impossibilidade de dormir dão lugar a um ciclo vicioso, pois quanto mais o indivíduo tenta dormir, mais frustrado e incomodado se sente, o que acaba dificultando o sono.(10)
\end{abstract}

Os transtornos primários do sono são subdivididos em dissonias e parassonias, os primeiros caracterizam-se pelo fato de produzir excessiva sonolência durante o dia e também a dificuldade de manter e iniciar o sono; já o segundo é caracterizado por condutas fora da normalidade que se associem ao sono como o sonambulismo e solilóquio. ${ }^{(10)}$

Segundo Clemente ${ }^{(11)}$ a insônia a é uma queixa subjetiva experimentada de forma particular por cada doente ela pode ser classificada de acordo com a frequência, a duração, e também de acordo com sua etiologia, sendo:

Insônia Leve: Prejudica bem timidamente o desempenho profissional e social, é frequente, no entanto não corre todas as noites.

Insônia Moderada e Grave: Ambas ocorrem todas as noites, deixando muitos prejuízos durante o dia, porém na insônia grave o prejuízo social e profissional é ainda maior, pois o doente pode até deixar de trabalhar.

Insônia Aguda: Tem uma duração inferior a um mês, geralmente é atribuída à medicação ou fatores ambientais.

Insônia sub-aguda ou de curta duração: Ela pode durar de 1 a 6 meses.

Insônia Crônica: Sua duração geralmente é superior a 6 meses, e pode ser recorrente por muitos anos.

Insônia Primária: Pode ser classificada em: idiopática, psicofisiológica ou paradoxal, sendo independente de outros distúrbios e condições, onde os fatores comportamentais, cognitivos

Volume 1, Número 1 - Abril, 2015. 
e fisiológicos exercem um papel etiológico predominante sendo: a insônia Idiopática surge na infância e evolui persistentemente por toda vida; a insônia psicofisiológica é causada por uma resposta mal adaptativa que foi condicionada já a insônia paradoxal a percepção do sono é distorcida, contradizendo com a realidade do que normalmente ocorre.

Insônia Secundária: É causada por outros distúrbios, médicos ou mentais como drogas ou outras substancias e também por hábitos de vida que podem não estar sendo compatíveis com o sono.

Com a ocorrência da insônia, os períodos da vigília serão sempre afetados de uma forma significativa, tanto nas alterações de comportamento e humor como também na predisposição física causada por períodos de extrema sonolência ao longo do dia. ${ }^{(12)}$

\subsection{Diagnóstico da Insônia}

Existem certas dificuldades e limitações quanto ao diagnóstico da insônia, isso se deve a falta de precisão da variação individual nas características do sono. ${ }^{(12)}$

Conforme Associação de Psiquiatria Americana ${ }^{(13)}$ estão definidos os critérios usados no diagnóstico da insônia.

Quadro 1: Critérios diagnósticos para a insônia primária

A queixa predominante é de dificuldade em iniciar ou manter o sono, ou de sono não
reparador, pelo período mínimo de um mês.
O distúrbio do sono (ou fadiga diurna associada) causa sofrimento clinicamente significativo
ou prejuízo no funcionamento social ou ocupacional ou em outras áreas importantes da
vida do indivíduo.
O distúrbio do sono não ocorre exclusivamente durante o curso de Narcolepsia, Transtorno
do Sono Relacionado à Respiração, Transtorno do Ritmo Circadiano do Sono ou de uma
Parassonia.
O distúrbio não ocorre exclusivamente durante o curso de outro transtorno mental (ex,
Transtorno Depressivo Maior, Transtorno de Ansiedade Generalizada. delirium).
O distúrbio não é devido aos efeitos fisiológicos diretos de uma substância (ex, droga de
abuso, medicamento) ou de uma condição médica geral.

Fonte: DSM - IV..$^{(13)}$

O diagnóstico eficaz de indivíduo que sofre insônia é necessário, uma anamnese detalhada que se refira aos comportamentos que se relacionem ao sono, ou mesmo a falta dele deve ser feita. Há certos casos em que se diagnosticar a insônia se torna mais difícil

Volume 1, Número 1 - Abril, 2015. 
tornando necessária a utilização do laboratório do sono, onde são realizadas as avaliações comportamentais e fisiológicas. ${ }^{(14)}$

\subsection{Diagnóstico Diferencial da Insônia}

De acordo com o DSM - IV ${ }^{(13)}$, entende-se que a duração do sono considerado "normal", pode consideravelmente variar, em alguns indivíduos que possuem uma pouca necessidade de sono, ou seja, aqueles que dormem pouco e se preocupam com a duração de seu sono, os mesmos são diferenciados dos indivíduos que possuem insônia primária pelo fato da ausência de sintomas característicos e também pela sua facilidade em conciliar o sono, dentre outros ainda à insônia deve se diferenciar de:

Hipersonia Primária: Ocorre quando a sonolência diurna é considerada em decorrência da insônia, não sendo tão grave.

Transtorno do Ritmo circadiano do Sono: Distingue-se da insônia pelo fato de um histórico recente de troca de turno no trabalho ou também mudanças de fuso horário.

Narcolepsia: Pode causar queixas semelhantes à insônia, no entanto diferencia-se da mesma por sintomas de sonolência diurna, cataplexia, alucinações que estejam relacionadas ao sono e paralisia do sono.

Transtorno do Sono relacionado à respiração: $A$ insônia primária é diferenciada, pois nos transtornos do sono relacionados a respiração a uma grande incidência de roncos altos, pausas respiratórias, e sonolência excessiva durante o dia.

Parassonias: São queixas de comportamentos ou eventos que normalmente não ocorrem durante o sono, provocando vários despertares durante o período do sono.

Insônia relacionada com outro transtorno mental: Diagnóstico que deve ser levado em consideração apenas quando a insônia for a queixa predominantemente grave, até o ponto de necessitar de atenção clínica.

Transtorno do sono devido a uma condição médica geral, do tipo Insônia: Acontece que a insônia é considerada como uma consequência fisiológica determinante de uma condição médica geral.

Transtorno do sono induzido por substância, tipo insônia: É distinguido da insônia primária, pois neste caso uma substância é a causa da insônia.

Transtornos do sono que incluem a insônia como característica essencial ou associada: Não pode ser diagnosticada a Insônia Primária quando a insônia ocorre exclusivamente dentre o curso de um outro transtorno mental.

\subsection{Evolução e Manutenção da insônia}

Há pessoas que apresentam uma maior predisposição para desenvolver a insônia do que outras, durante a infância e a adolescência, a insônia primária ocorre de forma menos frequente, geralmente tem início entre 20 e 30 anos de idade e vai se intensificando Volume 1, Número 1 - Abril, 2015. 
gradativamente. Nas mulheres existe uma maior predisposição genética, pois a insônia primária é diagnosticada frequentemente mais em mulheres do que nos homens. ${ }^{(10)}$

Segundo o DSM - IV ${ }^{(13)}$, na grande maioria dos casos, o início dos sintomas da insônia é repentino e podem acontecer em momentos de estresse psicológico, social e médico, sendo que a insônia primária ainda irá persistir por um tempo excessivamente longo devido ao condicionamento negativo; em contrapartida em alguns casos o desenvolvimento da insônia primária desenvolve-se aos poucos, onde não há um estressor bem definido.

\section{A PSICOTERAPIA COGNITIVO-COMPORTAMENTAL E O TRATAMENTO DA INSÔNIA}

O tratamento da insônia primária deve combinar intervenções farmacológicas e também intervenções não farmacológicas, isso pelo fato de que a insônia primária é um transtorno que possui vários aspectos clínicos. ${ }^{(10)}$

O tratamento psicológico visa principalmente aliviar os sintomas, enquanto a psicologia tem uma importância no tratamento das causas.

No tratamento não farmacológico da insônia estão inclusos a higiene do sono, controle de estímulos, restrição do tempo na cama e a Terapia Cognitiva; essa medida de tratamento possui um efeito mais duradouro do que as medidas farmacológicas, sendo obtida uma melhoria significativa tanto na quantidade como na qualidade do sono, no entanto a combinação das duas medidas de intervenções também pode surtir um efeito bastante eficaz, é importante se levar em consideração que a terapêutica farmacológica pode resultar em efeitos adversos, principalmente quando usada de forma inadequada, em quantidades maiores do que as recomendadas ou em combinação com bebidas alcoólicas, podendo desencadear uma lentificação cognitiva e psicomotora. ${ }^{(16)}$

A eficácia do tratamento da insônia determina-se por melhorias na qualidade do sono e também no funcionamento diário, o tratamento deve possuir um direcionamento na tentativa de reverter à causa que provocou e que mantém a insônia; as estratégias de intervenção são singulares, pois iram variar a partir da queixa de cada paciente. ${ }^{(4)}$

As sessões de terapia para o tratamento da insônia são semanais podendo variar entre 30 e 90 minutos com uma duração que irá alternar de quatro a oito semanas, levando-se em conta a diminuição da queixa e também o estágio do tratamento. ${ }^{(16)}$

\subsection{Componentes da Terapia}

A Terapia Cognitivo-Comportamental (TCC) é uma proposta terapêutica baseada em intervenções estruturadas e objetivas, abordando fatores cognitivos, comportamentais e Volume 1, Número 1 - Abril, 2015. 
emocionais, no tratamento de transtornos psiquiátricos. ${ }^{(17)}$ É constituída a partir da união de técnicas e conceitos das abordagens cognitivas e comportamentais. ${ }^{(18)}$

Para Wright et al. ${ }^{(20)}$, a (TCC), é uma abordagem baseada em dois princípios fundamentais; nossas cognições influenciam nossas emoções e comportamentos e nossos comportamentos estão intimamente relacionados com nossas emoções e pensamentos.

A terapia cognitivo-comportamental da insônia (TCC - I) é composta por uma gama de diferentes procedimentos e técnicas com a finalidade de diminuir ou modificar as variáveis mantenedoras da insônia. ${ }^{(16)}$ Sendo as principais:

Higiene do Sono: A higiene do sono se refere a estabelecer e promover condições que sejam adequadas a um sono tranquilo e saudável, relacionando - se a três pontos que são fundamentais, o horário, o ambiente e as atividades que antecedem ao sono. ${ }^{(21)}$ Trata se de uma intervenção psico-educacional com a finalidade de agir contra fatores que estejam mantendo a insônia. ${ }^{(16)}$

Fatores que irão contribuir para a higienização do sono:

- O ambiente de dormir deve proporcionar um clima agradável;

- O horário de dormir e acordar deve respeitar um horário uniforme;

- Evitar se exercitar demasiadamente antes de se deitar;

- Evitar a ingestão de bebidas alcoólicas e também o uso de tabaco antes de dormir;

- Evitar o uso de bebidas estimulantes ou que contenham cafeína desde o início da noite;

- Deixar que a cama seja de uso exclusivo para dormir;

- Diminuir ou evitar as sestas e os cochilos durante o dia;

- Deixar que atividades excitantes sejam realizadas durante o dia e não antes de dormir. ${ }^{(20)}$

Os aspectos que compõe a higiene do sono são hábitos saudáveis que farão com que seja obtido o máximo de benefícios das horas dormidas, são medidas úteis que irão favorecer a qualidade e também a quantidade do sono.

Controle de Estímulos: Baseia-se no fato de que a insônia é resultante de um processo condicional mal adaptativo do paciente em relação ao ato de ir para a cama e o ambiente de dormir. ${ }^{(20)}$

A terapia de controle de estímulos é apropriada para o os doentes que foram condicionados a associar a cama, ou sono, em geral a algo negativo. Essa associação negativa pode ter sido desenvolvida após um evento desencadeador, nomeadamente doença médica ou psiquiátrica, ou um fator psicossocial estressante.(15)

Volume 1, Número 1 - Abril, 2015. 
Para Clemente ${ }^{(11)}$ o objetivo da Terapia de Controle de Estímulos é recondicionar novamente o sono a cama reforçando a interação dos comportamentos de dormir com os estímulos do ambiente e eliminar os comportamentos que não são compatíveis com o sono. A autora ainda menciona que é necessária a aplicação de alguns procedimentos para que isso se torne possível, sendo:

- Não dormir durante o dia;

- Deixar o quarto restrito apenas para dormir e realizar atividade sexual;

- Ir para a cama somente quando sentir sono;

- Ter um horário para se levantar, não levando em conta a duração do sono durante a noite; - Após deitar, se não conseguir adormecer entre 15 e 20 minutos, partir para outra parte da casa, procurando atividades calmas, e retornar para cama apenas quando sentir sono;

- O procedimento acima citado deve ser repetido quantas vezes for necessário até que se tenha sono.

Restrição do tempo na cama: A Terapia de restrição do tempo na cama tem como finalidade o aumento da eficiência do sono, por meio da privação temporária do sono, onde o tempo que se passa na cama é consideravelmente reduzido de forma voluntária. ${ }^{(11)}$

Os pacientes que possuem insônia normalmente tendem a tentar recompensar o tempo não dormido deitando-se mais cedo do que o normal e permanecendo na cama após acordarem, muitos destes acreditam que esses períodos passados na cama podem ser restauradores mesmo com o fato de não ter tido efetivamente o sono, no entanto esse tempo em excesso na cama aumenta o estado de alerta, o que acaba por reforçar a tentativa frustrada do paciente de não conseguir dormir. Assim o objetivo da Terapia de restrição do sono é propor ao paciente que ele permaneça na cama somente quando estiver realmente dormindo. ${ }^{(20)}$

Terapia Cognitiva: Para Clemente ${ }^{(11)}$ o tratamento da insônia por meio da terapia cognitiva é composto por técnicas de reestruturação cognitiva, que possibilitem ao paciente a identificação e também a correção de seus pensamentos distorcidos, em relação as suas atribuições sobre a insônia.

A reestruturação cognitiva nas sessões de terapia permite ao paciente identificar os pensamentos automáticos e os esquemas e por meio destes aprender habilidades com o intuito de modificar as cognições distorcidas, a partir daí é necessário que o paciente realize uma série de alguns exercícios, para aproximar o aprendizado da terapia a questões situacionais do mundo real. ${ }^{(19)}$

Cavadas e Ribeiro ${ }^{(15)}$ enfatizam que para que haja a reestruturação sobre as crenças errôneas a respeito da insônia crenças é preciso acabar com as expectativas irrealistas do paciente sobre o sono como, por exemplo: "preciso dormir nove horas por noite", desmistificar Volume 1, Número 1 - Abril, 2015. 
a respeito das reais causas mantenedoras da insônia, exemplo: "sou desequilibrado e isso é a causa da minha insônia", ampliar consequências sobre uma noite mal dormida: a exemplo: "não consigo fazer nada corretamente depois de uma noite mal dormida", trabalhar a ansiedade e a perda de controle em relação a capacidade de dormir, exemplo: "vou perder o controle em relação a minha capacidade de dormir".

Assim o objetivo da terapia cognitiva da insônia é tentar modificar as crenças não adaptativas a respeito do sono e também da insônia, e a partir disso reduzir os efeitos de tais atribuições que prolongam o estado da vigília. ${ }^{(22)}$

\section{CONCLUSÃO}

Diante do exposto pode se perceber que o sono exerce fundamental importância para o funcionamento adequado do organismo humano, sendo responsável pela manutenção de um equilíbrio físico e psicológico. No entanto vários podem ser os fatores que desencadeiam alterações do sono, revertendo significativamente à função primordial do sono de reparação e restauração.

Dentre as alterações do sono a de maior ocorrência é a insônia, o diagnóstico precoce é de grande valia podendo evitar a ocorrência de transtornos secundários desencadeados a partir da mesma.

O tratamento da insônia apesar de contar com grandes avanços ainda se depara com diversas limitações, tendo início desde o diagnóstico até a erradicação total dos sintomas que mantém a insônia. Ainda existe uma necessidade muito grande de ampliar este campo de estudo, para que não existam leigos no assunto se tratando de um problema que afeta grande parte da população geral. A TCC se revela como uma forte medida terapêutica, pois ela traz grandes benefícios ao paciente insone com efeitos mais rápidos e eficazes revertendo o que está mantendo a insônia.

Sendo assim o psicólogo possuí um papel fundamental nesta ação cabe a ele promover desde a prevenção a reabilitação dos pacientes insones por meio de orientações que irão facilitar a eficácia no tratamento.

\section{REFERÊNCIAS}

1. SADOCK, V. A.; SADOCK, B. J.; Compêndio de Psiquiatria: ciência do comportamento e psiquiatria clínica. 9 ed. Porto Alegre: Artmed, 2007.

Volume 1, Número 1 - Abril, 2015. 
2. MARTINS, P. J. F.; MELLO, M. T.; TUFIK, S. Exercício e Sono. Revista Brasileira de Medicina do Esporte. São Paulo. 2001;7(1):28-36.

3. MARTINO, M. M. F. Arquitetura do sono diurno e ciclo vigília - sono em enfermeiros nos turnos de trabalho. Revista da Escola de Enfermagem USP. São Paulo. 2009;43(1):194-199.

4. RIOS, A. L. M.; PEIXOTO, M. F. T.; SENRA, V. L. F. Transtornos do Sono, Qualidade de vida e tratamento psicológico. 2008. 52 f. Monografia (Graduação em Psicologia) Universidade Vale do Rio Doce, Governador Valadares, 2008.

5. ALÓE, F.; AZEVEDO, A. P.; HASAN, R. Mecanismos do sono vigília. Revista Brasileira de Psiquiatria. São Paulo. 2005;27(1):33-39.

6. VIGETA, S. M. G. Alterações do sono e menopausa: uma revisão da literatura. Revista Ciência Cuidado e Saúde. São Paulo. 2007;6(3):377-383.

7. TOGEIRO, S. M. G.; SMITH, A. K. Métodos diagnósticos nos distúrbios do sono. Revista Brasileira de Psiquiatria. São Paulo. 2005;27(1):8-15.

8. FERNANDES, R. M F.; O sono Normal. Revista Medicina Ribeirão Preto - USP. Ribeirão Preto. 2006;39(2):157-168.

9. SÁ, R. M. B.; MOTTA, L. B.; OLIVEIRA, F. J. Insônia: Prevalência e fatores de risco relacionados em população de idosos acompanhados em ambulatório. Revista brasileira de Geriatria e Gerontologia. Rio de Janeiro. 2007;10(2):217-230.

10. MONTI, J. M. Insônia Primária: diagnóstico diferencial e tratamento. Revista Brasileira de Psiquiatria. Montevidéu. 2000;22(1):31-34.

11. CLEMENTE, V. Como tratar os doentes com insônia crônica? O contributo da Psicologia Clínica. Revista Portuguesa de Clínica Geral, Coimbra. 2006;22(5):635 - 644.

12. ALVES, R. S. C.; EJSENBERG. B.; OKAY, Y. Revisão das desordens do sono com excessiva movimentação, insônia e sonolência na criança. Revista de Pediatria. São Paulo. 2002;24(1):50-64.

13. American Psychiatric Association. Manual diagnóstico e estatístico de transtornos mentais. Texto revisado, DSM - IV TR. Porto Alegre: Artmed, 2003.

14. DALGALARRONDO, P. Psicopatologia e semiologia dos transtornos mentais. 2 ed. São Paulo: Artmed, 2008.

15. CAVADAS, L. F.; RIBEIRO, L. Abordagem da insônia secundária do adulto nos cuidados de saúde primário. Revista Acta Médica Portuguesa. Portugal. 2011;24(1):135-144.

16. MOREIRA, E. A. Terapia Comportamental Cognitiva da insônia: um protocolo de atendimento. 2010. 42 f. Monografia (Especialização em Psicologia) - Instituto de Psicologia, Universidade Federal de Uberlândia, Uberlândia, 2010.

17. DUCHESNE, M.; ALMEIDA, P. E. M. Terapia Cognitivo Comportamental dos Transtornos Alimentares. Revista Brasileira de Psiquiatria. São Paulo. 2002;24:49-53.

Volume 1, Número 1 - Abril, 2015. 
18. BAHLS, S. C; NAVOLAR, A. B. B. Terapia Cognitiva Comportamental: Conceitos e Pressupostos Teóricos. Revista Eletrônica de Psicologia. Curitiba. 2004(4).

19. WRIGHT, J. H; BASCO, M. R; THASE, M. E. Aprendendo a Terapia CognitivoComportamental. Porto Alegre: Artmed, 2008.

20. BERLIM, M. T. et al. Diretrizes e algoritmo para o manejo da insônia. Porto Alegre: Artmed, 2005. p. 385.

21. NUNES, M. L.; CAVALCANTE, V. Avaliação clínica e manejo da insônia em pacientes pediátricos. Jornal de Pediatria do Rio de Janeiro. Porto Alegre. 2005;81(4).

$75572005000500004 \&$ Ing=en\&nrm=iso

22. MORIM, C. M. Contribtions of cognitive-behavioral approaches to the clinical management of insomnia. The Primary Care Companion to The Journal of Clinical Psychiatry. Memphis. 2002(4):21-26.

Volume 1, Número 1 - Abril, 2015. 